\title{
PENDAMPINGAN PENGENALAN METODE PENGETIKAN CEPAT MENGGUNAKAN MICROSOFT WORD BAGI SISWA KELAS 5 SD IT SALSABILA AL MUTHI'IN, YOGYAKARTA
}

\author{
Dwi Nugraheny $^{1}$, Hero Wintolo ${ }^{2}$, Anggraini Kusumaningrum ${ }^{3}$, \\ Sudaryanto $^{4}$, Haruno Sajati ${ }^{5}$ \\ Program Studi Teknik Informatika \\ Sekolah Tinggi Teknologi Adisutjipto, Yogyakarta \\ J1. Raya Janti Blok R Lanud Adisutjipto, Yogyakarta \\ Email : ${ }^{1)}$ henynug@stta.ac.id, ${ }^{2)}$ herowintolo@stta.ac.id, ${ }^{3)}$ anggraini@stta.ac.id, \\ ${ }^{4)}$ sudaryanto@stta.ac.id, ${ }^{5}$ harunosajati@stta.ac.id
}

\begin{abstract}
Information and Communication Technology (ICT) in today's world is needed by every community, both adults and children. Especially for children, training in the use of information and communication technology devices is needed so that children can use them later. One of them is to introduce the use of word processing applications, namely Microsoft Word. Microsoft Word is a word processing application that is very popular at this time, with the application can facilitate human work in typing letters and other documents. Children can be taught the application to support their daily activities in academic activities at school. This semester's community service activities are emphasized in the form of Mentoring for Introduction to Fast Typing Methods using Microsoft Word 2010 Software for 5th grade students at SDIT Salsabila Al Muthi' in Yogyakarta. It is expected that the assistance, students can find out more about the parts of the Microsoft Word Application and their use so that they can help with schoolwork and enhance creativity. The results of the service activities carried out provide experience and skills to students at SDIT Salsabilla Al-Muthi'in in using Microsoft Word 2010 applications.
\end{abstract}

Keywords: Information Technology, Communication, Microsoft Word

\begin{abstract}
Abstrak
Teknologi Informasi dan Komunikasi (TIK) pada jaman sekarang sangat dibutuhkan oleh setiap masyarakat baik itu orang dewasa maupun anak-anak. Khusus pada anak-anak, sangat dibutuhkan pelatihan penggunaan perangkat teknologi informasi dan komunikasi agar nantinya anak-anak dapat memanfaatkannya dengan baik. Salah satunya adalah dengan mengenalkan penggunaan aplikasi pengolah kata yaitu Microsoft Word. Microsoft Word adalah aplikasi pengolah kata yang sangat populer pada saat ini, dengan aplikasi tersebut dapat memudahkan kerja manusia dalam melakukan pengetikan surat maupun dokumen lain. Anak-anak dapat diajarkan aplikasi tersebut guna mendukung kesehariannya dalam kegiatan akademik di sekolah. Kegiatan pengabdian pada masyarakat semester ini dititikberatkan dalam bentuk Pendampingan Pengenalan Metode Pengetikan Cepat menggunakan Software Microsoft Word 2010 bagi siswa-siswi kelas 5 di SDIT Salsabila Al Muthi'in Yogyakarta. Diharapkan adanya pendampingan tersebut, siswa/siswi dapat lebih mengetahui tentang bagian-bagian Aplikasi Microsoft Word dan penggunaannya sehingga dapat membantu saat pengerjaan tugas sekolah maupun meningkatkan kreativitas. Hasil dari kegiatan pengabdian yang dilaksanakan memberikan pengalaman dan ketrampilan pada para siswa di SDIT Salsabilla Al-Muthi'in dalam menggunakan aplikasi Microsoft Word 2010.
\end{abstract}

Kata Kunci: Teknologi Informasi, Komunikasi, Microsoft Word 


\section{Latar Belakang Masalah}

SDIT Salsabilla Al-Muthi' in merupakan salah satu sekolah dasar yang berbasis Islam Terpadu yang berada di kawasan Banguntapan, Bantul Provinsi Daerah Istimewa Yogyakarta. Jumlah siswa sampai tahun 2018 ini sebanyak 42 orang. Untuk konten mata pelajaran yang digunakan sudah berbasis kurikulum 2013, dimana salah satunya adalah mata pelajaran Prakarya yang memuat Teknologi Informasi dan Komunikasi.

Pada proses pembelajaran Teknologi Informasi dan Komunikasi (TIK) setiap tatap mukanya di SDIT Salsabilla Al-Muthi' in menggunakan model ceramah, dengan anakanak memperhatikan langsung Guru menjelaskan setiap materi, dan kemudian mempraktikkannya secara bergantian di depan kelas satu per satu anak. Hal tersebut tentunya kurang maksimal bila dijadikan latihan untuk meningkatkan ketrampilan anakanak dalam memahami materi yang disampaikan. Pada SDIT Salsabilla Al-Muthi' in sendiri fasilitas komputer yang disediakan terbatas, dengan kata lain belum mencukupi dengan jumlah siswa yang mengikuti kelas TIK. Sehingga dalam mempraktikkannya harus saling bergantian setiap siswa. Di samping itu, bahan ajar yang digunakan oleh guru masih terbatas jumlah sehingga perlu dilakukan penambahan resource materi sebagai penunjang kegiatan pembelajaran.

Pendampingan terhadap masyarakat yang dilakukan oleh dosen menjadi bagian dari Tri Dharma perguruan tinggi yang harus dilaksanakan setiap tahun minimal satu kali. Adapun bentuk pendampingan dalam pengabdian masyarakat ini dapat dilihat pada kegiatan dosen di perguruan tinggi lainnya di Indonesia [1-9]. Dengan demikian pelaksanaan pengabdian pada masyarakat dengan cara pendampingan terhadap siswa SD ini memiliki alur yang jelas dan tahapan dalam transfer knowledge dapat berjalan sesuai tujuannya.

\section{Masalah}

Berdasarkan analisis situasi dan permasalahan mitra di atas, kegiatan pengabdian ini menjadi solusi kebutuhan para siswa di SDIT Salsabilla Al-Muthi'in, melihat kondisi yang terjadi, perlu adanya pelatihan khusus yang menyediakan ruang untuk anak-anak mempraktikkan materi TIK yang pernah didapatkannya. Praktek ini bersifat mandiri, artinya setiap anak memegang satu komputer dengan harapan pemahaman dan pengujian materi lebih maksimal. Selain itu, memberi pengalaman pada anak-anak dalam mengimplementasikan dan mengembangkan materi TIK secara mandiri. Kegiatan pengabdian pada masyarakat dititikberatkan dalam bentuk Pendampingan Peningkatan Kemampuan Teknologi Informasi dengan menggunakan software Microsoft Word 2010, khususnya tenang pengenalan metode pengetikan cepat menggunakan Ms. Word.

\section{Metode Pelaksanaan Pengabdian}

Metode Pelaksanaan Pengabdian pada Masyarakat ini meliputi beberapa komponen yaitu:

a. Sumber Daya Manusia (SDM)

Metode yang dipilih untuk memenuhi kebutuhan SDM dengan melakukan pendataan terhadap Siswa Siswi Kelas 5 SD Salsabila Al Muthi'in dengan materi yang diberikan dalam pelatihan ini disesuaikan dengan kurikulum yang berlaku bagi SD tersebut.

b. Keterbatasannya fasilitas teknologi yang mendukung.

Keterbatasan fasilitas komputer untuk pelajaran Teknologi Informasi dan Komunikasi (TIK) karena belum adanya laboratorium komputer di SD tersebut, diselesaikan dengan mengadakan pelatihan dan pendampingan menggunakan komputer di laboratorium komputer STTA. 
c. Proses

Setelah dilakukan pengarahan dan pelatihan cara mengetik yang cepat dan baik menggunakan teknologi Informasi yaitu komputer, kemudian dilanjutkan dengan pendampingan dalam menggunakan software Microsoft Word 2010 disesuaikan dengan kurikulum yang berlaku bagi SD tersebut. Adapun proses pelaksanaan pendampingan dilakukan selama 3 (tiga) hari pada tanggal 21 sampai dengan 23 Mei 2018, di laboratorium Sekolah Tinggi Teknologi Adisutjipto Yogyakarta

d. Produk

Menghasilkan siswa siswi SD yang mampu mengetik yang cepat dan baik menggunakan teknologi Informasi yaitu komputer, dengan software Microsoft Word 2010.

e. Manajemen

Setelah melakukan sosialisasi, dilanjutkan dengan memberikan pendampingan kepada siswa siswi Kelas 5 SD Salsabila Al Muthi' in untuk dilatih dalam menggunakan perangkat lunak Microsoft Word 2010 tersebut hingga menguasai dengan baik.

Tabel 1. Penguasaan Siswa Siswi Kelas 5 SD Salsabila Al Muthi'in Terhadap pengetikan secara cepat dan baik menggunakan Microsoft Word 2010 sebelum pelatihan

\begin{tabular}{|c|c|c|c|c|c|c|}
\hline \multirow[t]{2}{*}{ Nama Siswa Siswi } & \multicolumn{3}{|c|}{ Teknik Pengetikan } & \multicolumn{3}{|c|}{ Pemahaman Software } \\
\hline & Baik & Cukup & Kurang & Baik & Cukup & Kurang \\
\hline $\begin{array}{l}\text { Lysandra Mutia Khansa Wardani } \\
\text { Syafana Ramandari } \\
\text { Muhammad Misbahul Munir } \\
\text { Faunia Nadi Raudha } \\
\text { Khansa Nadia Gadi Saputri } \\
\text { Jihan Tiara Radita Putri } \\
\text { Lambang Wicaksono } \\
\text { Altaf Surya Annawaf } \\
\text { Muhamad Alvin Wardani } \\
\text { Faiq Al Giffari } \\
\text { Adnan M.R } \\
\text { Gautama Farrel Nasywa Amanullah } \\
\text { Farhan Dwi Antoro } \\
\text { Hafiz Fuqan Nauval } \\
\text { Azzaki Mushthofa Insani } \\
\text { Muhammad Fauzan Daffa Abdillah } \\
\text { Figo Ahsan Biantara } \\
\text { Muhammad Ihsan Putra } \\
\text { Maheswara Helga Rararya } \\
\text { Axello Daiva Jagadhita } \\
\text { Fadhil Azzufar Al Ghozali } \\
\text { Vania Sani Atmoko } \\
\text { Afifah Khoirina Azahra } \\
\text { Ivory Aurellia Putri } \\
\text { Salsa Budi Setyanti }\end{array}$ & & & $\begin{array}{l}\text { V } \\
\text { V } \\
\text { V } \\
\text { V } \\
\text { V } \\
\sqrt{ } \\
\sqrt{ } \\
\sqrt{ } \\
\sqrt{ } \\
\sqrt{ } \\
\sqrt{ } \\
\sqrt{ } \\
\sqrt{ } \\
\sqrt{ } \\
\sqrt{ } \\
\sqrt{ } \\
\sqrt{ } \\
\sqrt{ } \\
\sqrt{ } \\
\sqrt{ } \\
\sqrt{ } \\
\sqrt{ } \\
\sqrt{ }\end{array}$ & & & $\begin{array}{l}\sqrt{ } \\
\sqrt{ } \\
\sqrt{ } \\
\sqrt{ } \\
\sqrt{ } \\
\sqrt{ } \\
\sqrt{ } \\
\sqrt{ } \\
\sqrt{ } \\
\sqrt{ } \\
\sqrt{ } \\
\sqrt{ } \\
\sqrt{ } \\
\sqrt{ } \\
\sqrt{ } \\
\sqrt{ } \\
\sqrt{ } \\
\sqrt{ } \\
\sqrt{ } \\
\sqrt{ } \\
\sqrt{ } \\
\sqrt{ } \\
\sqrt{ }\end{array}$ \\
\hline
\end{tabular}


Asma Fathiyya

Laila Aulani Nursiam

Cheryl Makaila Fasya

Ghaitsaa Zulfa Hasanah

Hafizh Rachmanindra

Hudson Ali Firdaus

Latif Lukman Rabani

Dzaki Taufiqurahman Santoso

Muhammad Khoirurroziqin

Erlangga Putra Wardhana

Nabil Azfa Aminuddin

Zaidan Alam

Farras Risqy A.H.S.

Fadhil Islamilovic

Farid Akmal Maulana

Izza Imam Akbar

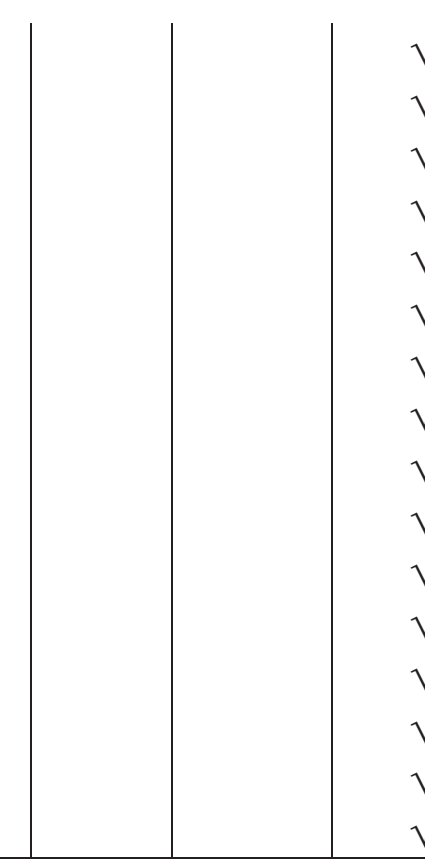

\begin{tabular}{l|l|l}
$\sqrt{ }$ \\
$\sqrt{ }$ \\
$\sqrt{ }$ \\
$\sqrt{ }$ \\
$\sqrt{ }$ \\
$\sqrt{ }$ \\
$\sqrt{ }$ \\
$\sqrt{ }$ \\
$\sqrt{ }$ \\
$\sqrt{ }$ \\
$\sqrt{ }$ \\
$\sqrt{ }$ \\
$\sqrt{ }$ \\
$\sqrt{ }$ \\
$\sqrt{ }$ \\
$\sqrt{ }$
\end{tabular}$|\quad| \begin{aligned} & \sqrt{ } \\
& \sqrt{ } \\
& \sqrt{ } \\
& \sqrt{ } \\
& \sqrt{ } \\
& \sqrt{ } \\
& \sqrt{ } \\
& \sqrt{ } \\
& \sqrt{ } \\
& \sqrt{ } \\
& \sqrt{ } \\
& \sqrt{ } \\
& \sqrt{ } \\
& \sqrt{ } \\
& \sqrt{ }\end{aligned}$

Kondisi awal para siswa SD yang mengikuti program pengabdian pada masyarakat ini kurang begitu baik dalam penguasaan keyboard komputer untuk melakukan proses pengetikan. Hal ini terlihat masih banyak yang menggunakan dua jari telunjuk kiri dan kanan saat mengetik. Begitu juga dari sisi pemahaman software yang digunakan untuk mengetik, sebagian besar belum familier dengan Microsoft Word 2010. Data ini dapat dilihat pada tabel 1, sedangkan pada tabel 2 didapatkan data setelah para siswa mengikuti proses pelatihan dalam pengabdian pada masyarakat ini.

Tabel 2. Penguasaan Siswa Siswi Kelas 5 SD Salsabila Al Muthi'in Terhadap pengetikan secara cepat dan baik menggunakan Microsoft Word 2010.

\begin{tabular}{l|c|c|c|c|c|c}
\hline \multirow{2}{*}{ Nama Siswa Siswi } & \multicolumn{2}{|c|}{ Teknik Pengetikan } & \multicolumn{2}{c}{ Pemahaman Software } \\
\cline { 2 - 7 } & Baik & Cukup & Kurang & Baik & Cukup & Kurang \\
\hline \hline Lysandra Mutia Khansa Wardani & $\sqrt{ }$ & & & $\sqrt{ }$ & & \\
Syafana Ramandari & & $\sqrt{ }$ & & $\sqrt{ }$ & \\
Muhammad Misbahul Munir & & $\sqrt{ }$ & & $\sqrt{ }$ & \\
Faunia Nadi Raudha & $\sqrt{ }$ & & & $\sqrt{ }$ & \\
Khansa Nadia Gadi Saputri & $\sqrt{ }$ & & & $\sqrt{ }$ & \\
Jihan Tiara Radita Putri & & $\sqrt{ }$ & & $\sqrt{ }$ & & \\
Lambang Wicaksono & $\sqrt{ }$ & & & $\sqrt{ }$ & & \\
Altaf Surya Annawaf & $\sqrt{ }$ & & & $\sqrt{ }$ & & \\
Muhamad Alvin Wardani & $\sqrt{ }$ & & & $\sqrt{ }$ & & \\
Faiq Al Giffari & $\sqrt{ }$ & & & & $\sqrt{ }$ & \\
Adnan M.R & $\sqrt{ }$ & & & & $\sqrt{ }$ & \\
Gautama Farrel Nasywa Amanullah & $\sqrt{ }$ & & & $\sqrt{ }$ & & \\
Farhan Dwi Antoro & $\sqrt{ }$ & & & $\sqrt{ }$ & & \\
Hafiz Fuqan Nauval & & $\sqrt{ }$ & & $\sqrt{ }$ & & \\
Azzaki Mushthofa Insani & & $\sqrt{ }$ & & $\sqrt{ }$ & & \\
Muhammad Fauzan Daffa Abdillah & $\sqrt{ }$ & & & $\sqrt{ }$ & &
\end{tabular}


Figo Ahsan Biantara

Muhammad Ihsan Putra

Maheswara Helga Rararya

Axello Daiva Jagadhita

Fadhil Azzufar Al Ghozali

Vania Sani Atmoko

Afifah Khoirina Azahra

Ivory Aurellia Putri

Salsa Budi Setyanti

Asma Fathiyya

Laila Aulani Nursiam

Cheryl Makaila Fasya

Ghaitsaa Zulfa Hasanah

Hafizh Rachmanindra

Hudson Ali Firdaus

Latif Lukman Rabani

Dzaki Taufiqurahman Santoso

Muhammad Khoirurroziqin

Erlangga Putra Wardhana

Nabil Azfa Aminuddin

Zaidan Alam

Farras Risqy A.H.S.

Fadhil Islamilovic

Farid Akmal Maulana

Izza Imam Akbar

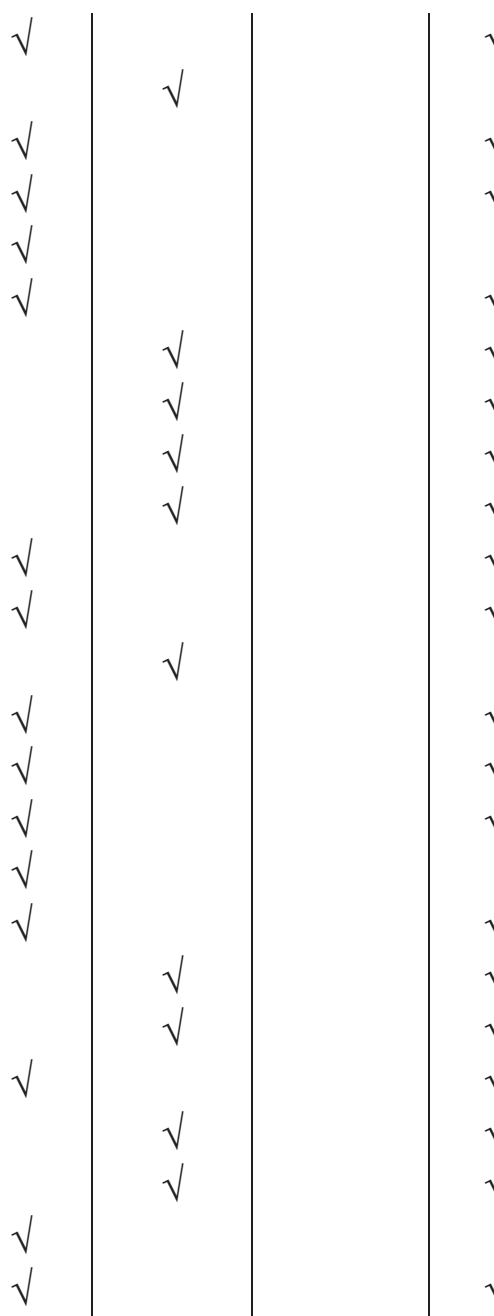

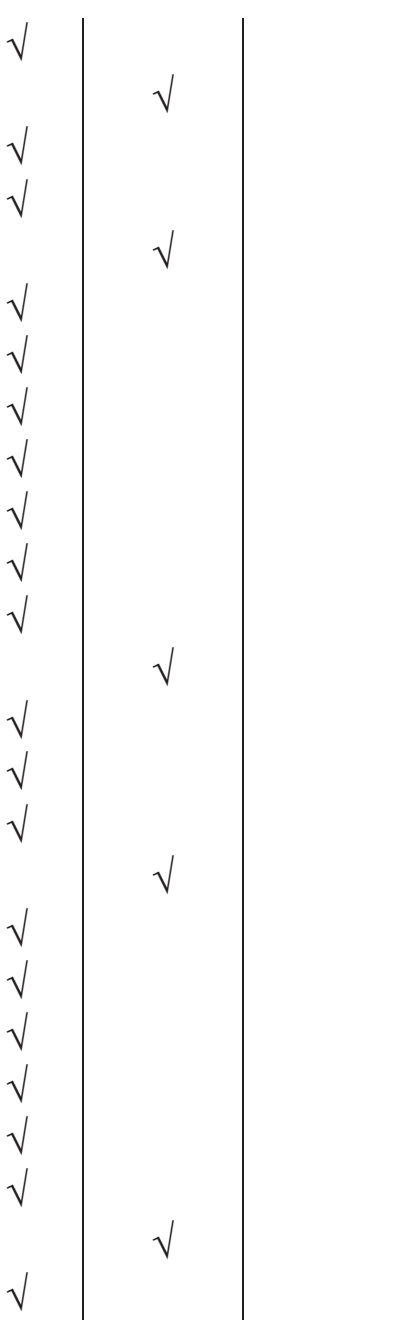

\section{Hasil dan Pembahasan}

Hasil luaran yang dicapai dari kegiatan pengabdian kepada masyarakat antara lain:

1. Adanya bahan ajar (modul) Teknologi Informasi dan Komunikasi (TIK) menggunakan aplikasi Microsoft Word 2010, untuk siswa siswi kelas 5 SD Salsabila Al Muthi'in. Modul bahan ajar dibuat sejumlah guru pendamping dan siswa siswi kelas 5 SD yang mengikuti pelatihan dan pendampingan. Adapun jumlah guru-guru SD Salsabila Al-Muthi'in yang mengikuti pendampingan siswa sejumlah 5 guru, dan siswa siswi sejumlah 41 siswa, dapat dilihat pada tabel 1.

2. Meningkatnya kompetensi bagi siswa siswi kelas 5 SD IT Salsabila Al-Muthi' in dalam mengetik menggunakan komputer.

3. Meningkatnya kompetensi TIK bagi siswa-siswi kelas 5 SD Salsabila Al Muthi'in dalam memanfaatkan aplikasi pengolahan kata "Microsoft Word 2010". 


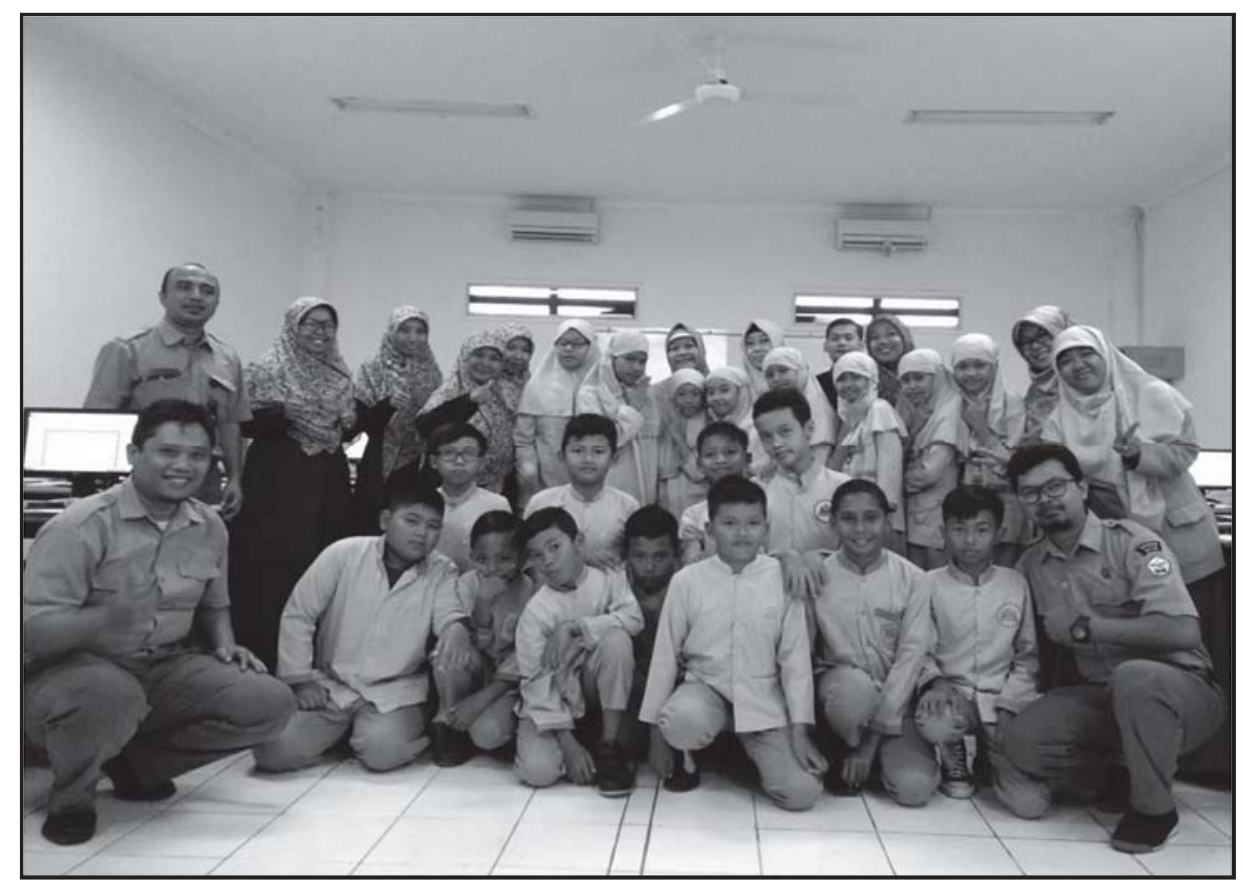

Gambar 1. Suasana Pendampingan Peningkatan Pengetikan cepat menggunakan software Microsoft Word 2010 bagi siswa siswi kelas 5 SD IT Salsabila Al-Muthi'in.

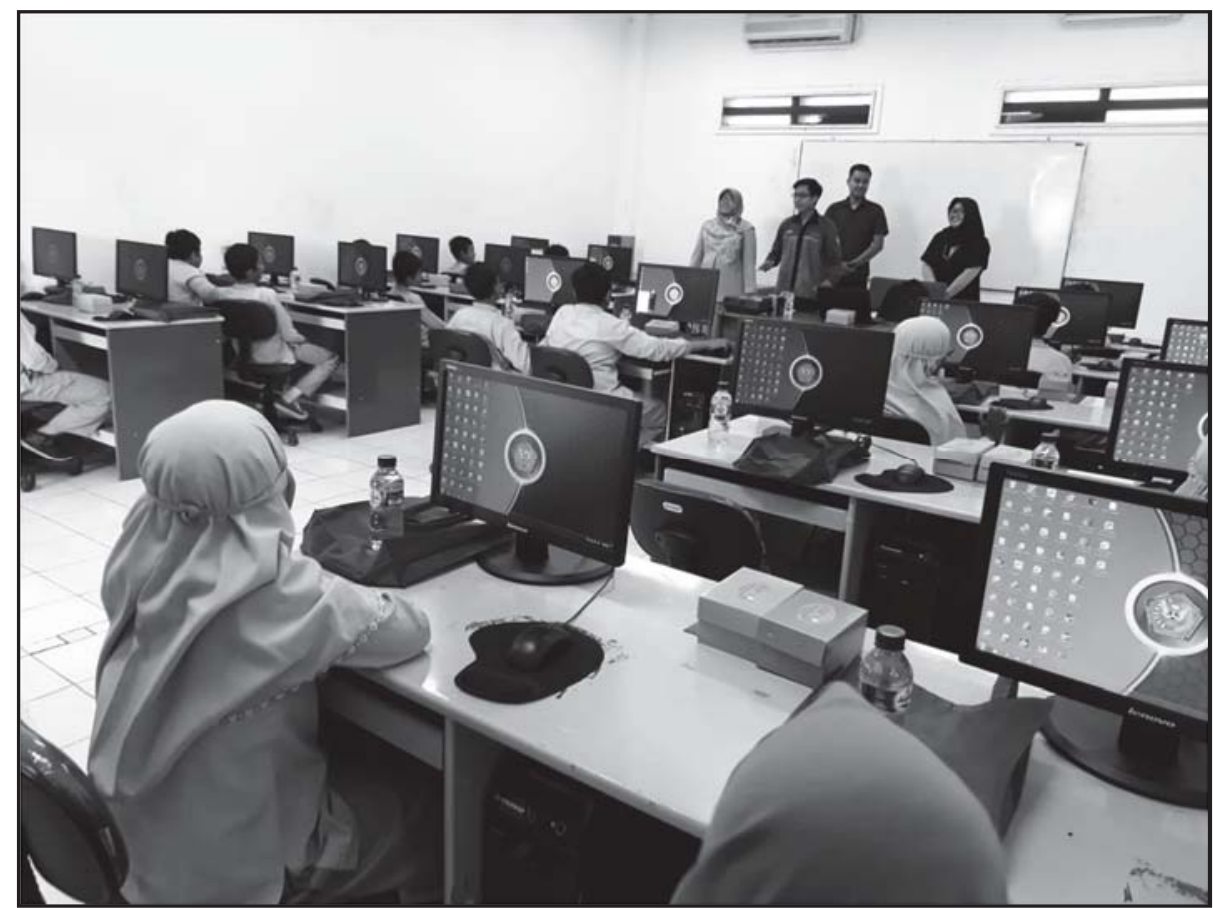

Gambar 2. Suasana Pendampingan Peningkatan Pengetikan cepat menggunakan software Microsoft Word 2010 bagi siswa siswi kelas 5 SD IT Salsabila Al-Muthi' in hari ke-1. 


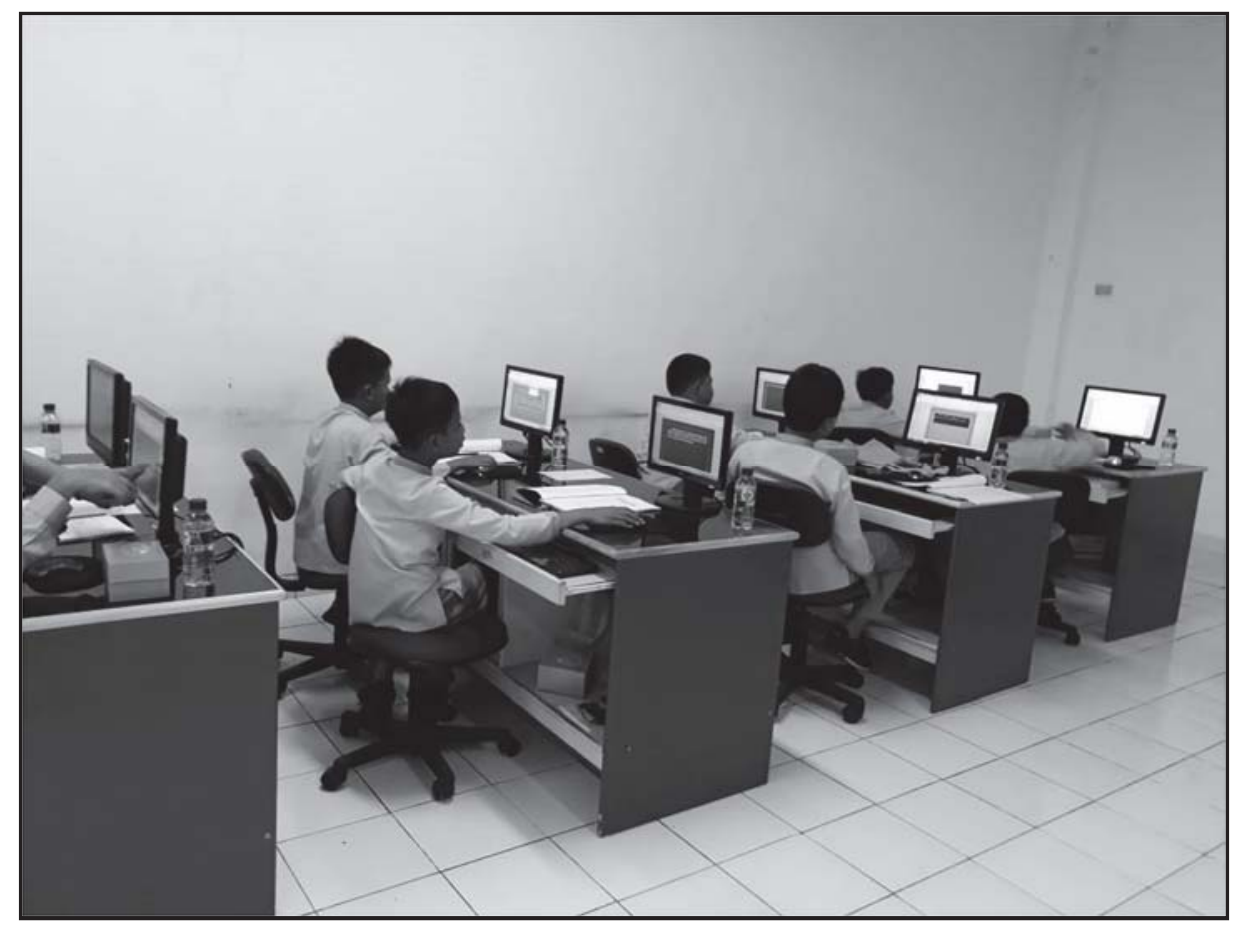

Gambar 3. Suasana Pendampingan Peningkatan Pengetikan cepat menggunakan software Microsoft Word 2010 bagi siswa siswi kelas 5 SD IT Salsabila Al-Muthi' in hari

\section{Kesimpulan}

ke-2.

Berdasarkan kegiatan pengabdian kepada masyarakat yang telah dilaksanakan selama 3 (tiga) hari, dapat diambil kesimpulan sebagai berikut:

1. Para siswa siswi lebih mengenal pengetikan secara cepat dan baik dalam menggunakan aplikasi Microsoft Word 2010.

2. Para siswa dapat mengetik lebih baik lagi dan menambah wawasan dalam memanfaatkan aplikasi pengolah kata seperti membuat artikel sesuai dengan mata pelajaran yang diajarkan.

3. Latihan yang telah dihasilkan dapat lebih mengembangkan minat siswa dalam bidang TIK.

\section{Daftar Pustaka}

[1] Ayuningtyas, A., Honggowibowo, A. S., Pujiastuti, A., Retnowati, N. D., \& Indrianingsih, Y. (2018). Pendampingan Pembuatan Bahan Ajar Bagi Guru Sekolah Dasar Islam Terpadu (SDIT) Salsabila Al Muthi'in Berbasis Multimedia dengan Menggunakan Microsoft Power Point. KACANEGARA Jurnal Pengabdian pada Masyarakat, 1(1), 1-6.

[2] Nugraheny, D., Wintolo, H., \& Kusumaningrum, A., Sudaryanto . (2018).

Pendampingan Pembuatan Bahan Ajar Berbasis Multimedia Menggunakan Macromedia Flash Bagi Para Guru SD IT Salsabila Al Muthi' in, Yogyakarta. KACANEGARA, 1(1), 23-28.

[3] Fitriyanto, N. A., Triatmojo, S., Pertiwiningrum, A., Erwanto, Y., Abidin, M. Z., Baliarti, E., \& Suranindyah, Y. Y. (2015). Penyuluhan dan Pendampingan Pengolahan Limbah Peternakan Sapi Potong di Kelompok Tani Ternak Sido Mulyo Dusun Pulosari, Desa Jumoyo, Kecamatan Salam, Kabupaten Magelang. Jurnal Pengabdian Kepada Masyarakat (Indonesian Journal of Community Engagement), 1(1), 79-95. 
[4] Widiastuti, A. (2015). Pendampingan Petani Stroberi di Desa Serang, Karangreja, Purbalingga, Jawa Tengah Dalam Manajemen Kesehatan Tanaman Melalui KKNPPM Universitas Gadjah Mada: Perlunya Bibit Stroberi Sehat dan Peningkatan Keterlibatan Petani dalam Kegiatan Kelompok. Jurnal Pengabdian Kepada Masyarakat (Indonesian Journal of Community Engagement), 1(1), 53-61.

[5] Marwasta, D. Pendampingan Masyarakat Desa Parangtritis dalam Pengelolaan Kawasan Gumuk Pasir melalui kegiatan Diversifikasi Usaha Berbasis Sumberdaya Pesisir. Jurnal Pengabdian Kepada Masyarakat (Indonesian Journal of Community Engagement), 2(2), 133-145.

[6] Marwasta, D. (2016). Pendampingan Pengelolaan Wilayah Perbatasan di Indonesia: Lesson Learned dari KKN-PPM UGM di Kawasan Perbatasan. Jurnal Pengabdian Kepada Masyarakat (Indonesian Journal of Community Engagement), 1(2), 204216.

[7] Mora, Z., Latief, A., \& Zainuddin, Z. (2018). Pelatihan Tenun Dari Limbah Lidi Kelapa Sawit Dengan Menggunakan Atbm Bagi Remaja Di Kabupaten Aceh Tamiang. Jurnal Pengabdian Kepada Masyarakat, 23(4), 432-439.

[8] Wahyuni, I. S. (2017). Pendidikan Kesehatan Mulut Melalui Pendekatan Metode Ceramah Dan Praktek (Studi Kasus Pelatihan Dokter Kecil Di Sekolah Dasar Alam). Jurnal Pengabdian Kepada Masyarakat, 1(5).

[9] Solihati, N. (2018). Pelatihan Aplikasi Teknologi Peternakan Pada Kelompok Integrasi Petani-Peternak Di Kecamatan Sukasari Kabupaten Sumedang. Jurnal Pengabdian Kepada Masyarakat, 1(1).

[10] Ristekdikti, R., \& Pustaka, U. (2016). Buku Panduan Pelaksanaan Penelitian dan Pengabdian kepada Masyarakat di Perguruan Tinggi EDISI X TAHUN 2016.

[11] Jarot, S., Shenia, A., \& Sudarma, S. (2012). Buku Pintar Microsoft Office 2007 \& 2010: Word-Excel-PowerPoint. MediaKita.

[12] Shelly, G. B., \& Vermaat, M. E. (2010). Microsoft Word 2010: Introductory. Cengage Learning. 